\title{
Aplicação de um modelo de avaliação de alinhamento estratégico em construtoras cearenses
}

\author{
Application of a model for measuring strategic alignment \\ in construction firms at Ceará
}

\begin{abstract}
George Silva Costa
José de Paula Barros Neto

luri Aragão de Vasconcelos

Marcella Facó Soares

Resumo

George Silva Costa Universidade Federal do Ceará Fortaleza - CE - Brasil

José de Paula Barros Neto Universidade Federal do Ceará Fortaleza - CE - Brasil

luri Aragão de Vasconcelos Universidade Federal do Ceará Fortaleza - CE - Brasil

Marcella Facó Soares Universidade Federal do Ceará Fortaleza - CE - Brasil

Recebido em 15/04/13

Aceito em 15/09/13

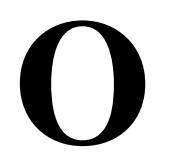

conceito de alinhamento estratégico vem ganhando espaço no mercado devido ao ambiente competitivo em que as empresas de construção estão inseridas. Apesar da sua importância, pouca atenção é dada à formulação de estratégias neste setor, sendo escassos os estudos que abordam este tema. De fato, é comum o problema de falta de alinhamento estratégico entre os níveis competitivo e funcional das empresas. $\mathrm{O}$ objetivo desta pesquisa consiste em desenvolver um método para analisar, medir e comparar o alinhamento entre as estratégias competitivas e as de produção em empresas de construção civil. Foi realizado estudo de campo em 14 construtoras de Fortaleza, CE. Em cada construtora dois representantes participaram da pesquisa, um membro do setor estratégico (diretoria) e outro do operacional (produção), sendo suas visões confrontadas. Com os resultados do grau de alinhamento estratégico de cada empresa, conclusões e sugestões quanto à aplicabilidade do modelo foram traçadas, assim como se realizou uma análise crítica do mesmo.

Palavras-chave: Alinhamento. Estratégia. Estratégia de produção. Empresas de construção.

\section{Abstract}

The concept of strategic alignment has been gaining ground in the market, due to the competitive environment in which construction firms operate. Despite its importance, little attention has been given to the formulation of strategies in this sector, and the literature on this topic is scarce. Indeed, the lack of strategic alignment between the competitive and functional levels is a common problem. The aim of this research work is to devise a method to analyse, measure and compare the alignment between the competitive and the production strategies of construction companies. A field study was conducted in 14 construction companies from Fortaleza, CE. In each company, two representatives took part in the investigation, a member of the strategic sector (board) and another from the operational sector (production), being their views compared. Based on the results of the degree of strategic alignment of each company, conclusions and suggestions about the applicability of the model were drawn, and a critical analysis of the model was undertaken.

Keywords: Alignment. Strategy. Production strategy. Construction companies. Model.
\end{abstract}




\section{Introdução}

Empresas em todo o mundo têm buscado colocar a estratégia no centro de seus modelos de gestão. $\mathrm{O}$ propósito é assegurar que a estratégia, como instrumento de comunicação e gestão, chegue a todos os níveis da organização e seja compartilhada. Esta tarefa de assegurar sinergias entre equipes, processos, unidades de negócio e parceiros externos denomina-se Alinhamento (KAPLAN; NORTON, 2006). Assim, a capacidade de alinhamento das organizações pode ser considerada um recurso estratégico capaz de produzir resultados superiores e constituir fonte de vantagem competitiva (POWELL, 1992).

Atualmente, esses conceitos vêm ganhando força, pois, visto o mercado competitivo em que as empresas então inseridas, estas não poderão desperdiçar seus recursos com estratégias mal formuladas, processos que não atendam às necessidades dos clientes ou com pessoas que não contribuam para a realização da estratégia (COSTA et al., 2009).

Portanto, o assunto alinhamento estratégico assume particular importância, pois desenvolver e implementar estratégias com a agilidade e a precisão necessárias pode fazer a diferença entre o sucesso e o fracasso de organizações. Mais ainda: a necessidade de se alinharem ações de rotina com metas estratégicas tem-se configurado em um diferencial na busca de solidez e lucratividade (COSTA; ROLA; AZEVEDO, 2009).

Nas empresas construtoras, que constituem um dos principais setores na formação do Produto Interno Bruto (PIB) do Brasil, esta realidade não é diferente, pois a concorrência tem-se mostrado relevante, e os clientes estão cada vez mais exigentes (ALVES; COSTA; BARROS NETO, 2009).

Vale lembrar que qualquer empresa tem sua estratégia como fruto das escolhas de seus dirigentes, porém, muitas vezes, elas não são explicitadas e pensadas de uma forma coerente e consciente. Juntamente com isso é preciso decidir em que nichos de mercado atuar, podendo competir em mercados diferentes (por exemplo, residencial e industrial), os quais precisam de estratégias distintas, nos diversos níveis (competitivo e funcional), com clientes que priorizam diferentes critérios na escolha dos produtos (COSTA, 2010).

Neste contexto, como exemplo de desalinhamento, tem-se que algumas empresas construtoras vêm investindo em programas de qualidade ou em novas tecnologias, mas nem sempre esses investimentos são bem-sucedidos e dão o retorno esperado. Isso pode ocorrer porque durante a tomada de decisão não se trabalha de maneira sistêmica e abrangente. Esses problemas podem decorrer de um processo realizado sem planejamento, com uma abordagem estratégica inadequada (BARROS NETO; ALVES, 2008), sem que todos na empresa compreendam os objetivos gerais, tendo percepções diferentes sobre a estratégia definida.

Assim, a justificativa para este trabalho se relaciona com a importância da estratégia no contexto competitivo e os reflexos de percepções diferentes sobre ela dentro das organizações por parte de seus integrantes. Considerando a importância da indústria da construção civil e suas características peculiares, há uma lacuna com relação a estudos sobre estratégia com foco na construção civil, notadamente com relação ao tema alinhamento estratégico (COSTA; VIEIRA; BARROS NETO, 2010). O problema de pesquisa é a carência de estudos que abordem a medição do alinhamento do conteúdo da estratégia vigente (percebida) entre o nível competitivo e o funcional.

Assim, o objetivo desta pesquisa consiste em desenvolver um método para analisar, medir e comparar o alinhamento entre as estratégias competitivas e as de produção em empresas de construção civil. Classifica-se o estudo como exploratório, e utilizou-se como estratégia de pesquisa o estudo de campo.

\section{Revisão bibliográfica}

Nesta seção, abordam-se os principais temas relacionados ao estudo: alinhamento estratégico, estratégia competitiva e estratégia de produção, pois estes temas se sobrepõem entre si, com contribuições diferentes em cada área e interações possíveis.

\section{Alinhamento estratégico}

Nos estudos sobre estratégia define-se o alinhamento com o sentido de ajuste, agrupamento, integração, coesão, congruência entre diferentes dimensões. Existem muitas definições e diversas classificações, além dos vários modelos existentes na literatura, para o termo "alinhamento estratégico" (KATHURIA; JOSHI; PORTH, 2007).

Alinhamento pode ser definido tanto como um padrão (processo para se atingir o alinhamento) quanto como um conteúdo (elementos a serem alinhados), também pode ser classificado como interno, externo e integrado (VENKATRAMAN; 
CAMILLUS, 1984). Aponta-se, ainda, a ideia de consenso, que se refere à concordância estabelecida tanto na formulação quanto na implementação da estratégia (PRIETO, 2006).

Kathuria, Joshi e Porth (2007) apresentam ainda duas classificações: alinhamento vertical e alinhamento horizontal. É vertical quando se refere aos vários níveis da organização, e horizontal quando se refere a funções (marketing, finanças, produção, entre outras). Henderson e Venkatraman (1993) concluem que alinhamento estratégico não é um evento, mas um processo de adaptação e mudança contínua.

No caso de estudos sobre estratégias de produção, alinhamento significa a coerência entre as atividades de produção e as políticas e práticas dela (SKINNER, 1969). Por exemplo, Kathuria e Partovi (1999 ${ }^{1}$ apud KATHURIA; JOSHI; PORTH, 2007) centraram-se no ajuste interno entre as prioridades da produção, em seu caso, flexibilidade, força de trabalho e práticas de gestão utilizadas pelos gestores de produção.

Wheelwright e Hayes (1985) mostram ainda que as estratégias de manufatura devem estar alinhadas com os objetivos estratégicos da corporação, visto que a função produção é uma das partes centrais de uma organização, pois produz seus bens e serviços.

Pires (1995), por sua vez, propõe um modelo de integração das atividades de planejamento e controle da produção a uma estratégia da manufatura, defendendo que as decisões sobre a manufatura precisam estar integradas com as decisões estratégicas das organizações. De forma similar, Slack et al. (1997) afirmam que decisões estratégicas em empresas devem envolver o planejamento estratégico da produção, apresentando coerência entre si.

Outro exemplo de estudo relacionando estratégia de produção e estratégia de negócio é o de Sun e Hong (2002), que faz uma abordagem também sobre a influência do alinhamento entre essas estratégias no desempenho da empresa, assim como Borella e Padula (2010), que analisam o alinhamento entre as estratégias de suprimentos, produção e distribuição com a estratégia de negócios da empresa e os reflexos no desempenho da empresa.

Resumindo, o dirigente tem de escolher a melhor estratégia para lidar com determinado mercado (estratégia competitiva), identificando como repassá-la para a função produção (estratégia de produção), visando garantir uma integração e

${ }^{1}$ KATHURIA, R.; PARTOVI, F. Y. Work force Management Practices For Manufacturing Flexibility. Journal of Operations Management, v. 18, n. 1 , p. 21-39, 1999. contínuo ajuste entre as atividades, para atingir um objetivo comum (alinhamento estratégico), de forma que os membros da empresa compreendam a estratégia dela.

\section{Estratégia competitiva}

Segundo Porter (1991), a base fundamental do desempenho acima da média é a vantagem competitiva sustentável. Para esse autor existem dois tipos básicos de vantagem competitiva: baixo custo e diferenciação. Esses dois tipos básicos de vantagem competitiva combinados dão origem a três estratégias genéricas: liderança em custo, diferenciação e enfoque - esta última pode variar em enfoque no custo e enfoque na diferenciação.

A primeira inferência que deve ser feita é que as estratégias de liderança no custo e de diferenciação buscam a vantagem competitiva em um limite amplo de segmentos, enquanto a estratégia de enfoque busca essa mesma vantagem em segmentos estreitos. A sustentabilidade das três estratégias genéricas exige que a vantagem competitiva de uma empresa resista à erosão pelo comportamento da concorrência ou pela evolução da indústria (CARVALHO; LAURINDO, 2007).

A liderança no custo, portanto, parte do pressuposto de que a empresa possui um escopo amplo e atende a muitos segmentos. Dessa forma, a intenção é estar em uma posição de comando em relação aos preços praticados naquele segmento. As vantagens de custo incluem a busca de economias de escala, tecnologia patenteada, acesso preferencial a matérias-primas, trabalhar constantemente para reduzir desperdícios, ou seja, fatores que proporcionam um diferencial de custo (PORTER, 1992).

Na estratégia de diferenciação, a empresa procura selecionar atributos que seu mercado consumidor considera importante. Dessa forma, a empresa pode se posicionar de maneira a atender a essas necessidades, buscando um preço diferenciado. A diferença pode ser baseada em um atributo do produto em si, ou pode ser baseada numa atividade de suporte ao produto, ou ainda no método de venda dele (PORTER, 1992).

Na estratégia de enfoque, a base é a escolha de um ambiente estreito dentro de um mercado. No enfoque em custo a intenção é explorar diferenças no comportamento dos custos em alguns segmentos, enquanto na diferenciação se exploram as necessidades particulares de certos compradores (PORTER, 1992). Geralmente esses segmentos surgem devido a um atendimento insatisfatório por concorrentes com alvos mais amplos. 
Por fim, o lema da estratégia competitiva é ser diferente, fazer algo inédito ou de uma forma diferente, dado que o cliente identifique esse diferencial e escolha determinada empresa em detrimento de seus concorrentes (COSTA; BARROS NETO, 2010).

\section{Estratégia de produção e critérios competitivos na construção civil}

A estratégia de produção divide-se em duas grandes áreas: processo e conteúdo. No estudo em questão, dar-se-á ênfase ao conteúdo de uma estratégia de produção que se divide em "critérios competitivos", relacionados com a estratégia competitiva da empresa, e "categorias de decisão", as quais orientam a tomada de decisões na função produção das empresas (BARROS NETO, 1999; PAIVA; CARVALHO; FENSTERSEIFER, 2009).

Com base no trabalho de Barros Neto (1999), definem-se critérios competitivos como um conjunto de prioridades consistentes que uma empresa tem de valorizar para competir no mercado. A distinção entre as estratégias de produção adotadas por diferentes empresas reside no peso que se atribui a cada um dos critérios competitivos e na forma como eles são efetivamente cumpridos no setor de produção.

Os critérios competitivos adaptados à construção civil (BARROS NETO, 1999) são custo, desempenho na entrega, qualidade, flexibilidade, inovação e serviços. De acordo com Barros Neto (1999) e Silva (1995), o custo é o critério mais perseguido pelas empresas construtoras. Porém, muitas vezes, as empresas não sabem muito claramente como reduzir estrategicamente seus custos. A produção tem papel fundamental na competição pelo menor custo por meio da atuação nos custos de produção, buscando menores custos e melhor adequação ao fluxo de caixa dos empreendimentos (BARROS NETO, 1999).

Em muitas indústrias o critério desempenho na entrega já é considerado qualificador (condição mínima), porém na construção de edificações o prazo de entrega é muitas vezes negligenciado pelas empresas, fazendo com que, em muitas ocasiões, a confiabilidade de entrega no prazo seja explorada como critério ganhador de pedido (diferencial competitivo), conforme explicita Barros Neto (1999).

O critério competitivo qualidade pode ser dividido em três dimensões: conformação com os contratos, conformação com os projetos e qualidade no processo construtivo. Este último é um dos mais valorizados pelos clientes, haja vista a percepção destes com referência ao acabamento e durabilidade, entre outras características do imóvel (BARROS NETO, 1999).

O conceito de flexibilidade é bastante amplo, dificultando sua operacionalização na construção. A mais evidenciada é a flexibilidade de produto, relacionada à facilidade que a empresa tem de adaptar seus produtos a um ou mais clientes, questionando-se o tipo de modificação, o quanto se poderá modificar e até quando poderão ser solicitadas modificações pelos clientes (BARROS NETO, 1999).

$\mathrm{Na}$ construção de edificações, o critério competitivo inovação fica evidente por meio de novas concepções arquitetônicas ou novos materiais de construção (produto) e novas formas de construir (processo). Neste último enquadra-se a construção enxuta, como filosofia inovadora e fonte potencial de diferenciais competitivos (BARROS NETO, 1999).

Destacam-se os serviços como uma das estratégias de diferenciação das empresas construtoras (CARDOSO, 1997² apud BARROS NETO, 1999). A prestação de serviços associados aos produtos vem sendo cada vez mais valorizada como um critério importante, visto que em muitas situações os produtos de empresas concorrentes são semelhantes em seus preços, prazos e desempenho; assim, o que acaba diferenciando uma empresa da outra é o contato com o cliente, seja no atendimento ou na assistência técnica, antes, durante e depois da entrega do produto (BARROS NETO, 1999).

\section{Metodologia}

A presente pesquisa consiste na aplicação do modelo desenvolvido por Costa (2010) em 14 construtoras de Fortaleza, CE, através de um estudo de campo, visando à obtenção de dados quanto ao alinhamento estratégico delas e, também, possibilitando uma melhor compreensão do modelo a partir de uma análise crítica de seu funcionamento.

Segundo Gil (2008), o estudo de campo é uma investigação empírica de um fenômeno dentro de seu contexto da vida real, produzindo evidências oriundas da verificação de materiais distintos, tais como documentos, registros em arquivos, questionários, entrevistas, observações, artefatos físicos, filmagens e fotografias. O mesmo é desenvolvido por observação direta das atividades do grupo estudado e por meio de entrevistas com

\footnotetext{
${ }^{2}$ CARDOSO, F. F. Estratégias Empresariais e Novas Formas de Racionalização da Produção no Setor de Edificações no Brasil e na França: parte 2: do estratégico ao tático. Estudos
}

Econômicos da Construção, v. 2, n. 3, p. 119-160, 1997. 
membros do local estudado (no caso, gerentes do operacional e da direção das empresas) para obter explicações e interpretações do que ocorre no campo.

O estudo de campo apresenta limitações quanto ao processo de generalização dos resultados da pesquisa, pois se procura estudar um grupo ou comunidade local sem caracterizar o universo ao qual pertencem, o que torna esse tipo de pesquisa subjetivo. Esse problema depende da capacidade do pesquisador em adequar o método empregado, bem como de manter um caráter imparcial durante as análises e estudos (GIL, 2008).

Essas empresas são de diversos tipos, desde as de pequeno porte até as de grande porte, com variados ramos de atividade, com o intuito de demonstrar suas diferenças de prioridade em relação à produção e os efeitos das diferenças no alinhamento estratégico. Duas pessoas foram entrevistadas em cada empresa: um representante da Diretoria e um da Produção.

A aplicação do modelo nas 14 empresas foi separada em duas partes: a primeira analisou, de forma aprofundada (entrevistas com dirigentes, análise de documentos), três construtoras (JA, PA e RQ); na segunda, aplicou-se o questionário reduzido às questões sobre perfil dos respondentes e da empresa, bem como sobre o alinhamento dos critérios competitivos, visando montar um gráfico representativo com uma amostra maior (sem cunho estatístico, mais 11 empresas escolhidas por critérios de acessibilidade).

\section{Descrição do modelo de mensuração de alinhamento estratégico}

$\mathrm{O}$ modelo desenvolvido visa à mensuração do alinhamento estratégico vertical para empresas da construção civil, analisando e quantificando a interação entre a visão de um membro da direção da empresa e outro da produção. O questionário é dividido em cinco partes com o intuito de obter informações variadas sobre a empresa. A Figura 1 descreve as fases do modelo, sua descrição, objetivo e em que fontes foi baseado.

Para o desenvolvimento do indicador, focou-se na Parte III (Figura 1), pois é nessa etapa que são coletados os dados pertinentes aos seis critérios competitivos (custo, qualidade, flexibilidade, desempenho na entrega, inovação e serviços). Através desses critérios é gerado o grau de alinhamento estratégico a ser expresso graficamente.

O foco do modelo, segundo Costa (2010), é a tomada de decisão da diretoria, sendo esta a maior interessada e também quem determina a visão estratégica da organização. Aos funcionários da produção cabe uma visão operacional, relacionada com a estratégia de produção, como pode ser mais bem observado na Figura 6.

Esta parte do questionário faz uso de escalas de gradação para medir as prioridades percebidas pelos setores, e cada afirmativa aborda um dos seis critérios apresentados acima. Assim, o questionário é aplicado a dois membros da empresa, de forma que pelo menos um seja da produção e o outro seja da diretoria, verificando-se as discrepâncias entre ambos, conforme exemplo da Figura 3.

Figura 1 - Procedimento de aplicação do modelo de alinhamento estratégico

\begin{tabular}{|c|c|c|c|}
\hline \multicolumn{4}{|c|}{ RESUMO DO QUESTIONÁRIO } \\
\hline PARTE & DESCRIÇÃO & FONTES PRINCIPAIS & OBJETIVOPRINCIPAL \\
\hline PARTE I & $\begin{array}{l}\text { Caracterização da } \\
\text { empresa }\end{array}$ & $\begin{array}{l}\text { Barros Neto (1999); } \\
\text { Barros Neto e Alves (2008); Costa (2003) }\end{array}$ & $\begin{array}{l}\text { Caracterizar as empresas, o seu } \\
\text { posicionamento no mercado }\end{array}$ \\
\hline $\begin{array}{l}\text { PARTE } \\
\text { II }\end{array}$ & Estratégia na Empresa & $\begin{array}{c}\text { Barros Neto e Alves (2008); Bruel, Santos e Moser } \\
\text { (2003); Costa (2003); Pongatichat e Johnston } \\
\text { (2008); Porter (1991; 1992); Silva (2003); } \\
\text { (em geral a seção 2.2) }\end{array}$ & $\begin{array}{l}\text { Conhecer as estratégias das empresas, } \\
\text { o processo de tomada de decisões e os } \\
\text { principais indicadores utilizados }\end{array}$ \\
\hline $\begin{array}{l}\text { PARTE } \\
\text { III }\end{array}$ & Critérios Competitivos & $\begin{array}{c}\text { Barros Neto (1999); Costa (2003); Cragg, King e } \\
\text { Hussin (2002); Silva (2003); Joshi, Kathuria e } \\
\text { Porth (2003); } \\
\text { (em geral a seção 2.3) }\end{array}$ & $\begin{array}{l}\text { Saber como as empresas trabalham } \\
\text { cada um dos critérios analisados e } \\
\text { quais são priorizados }\end{array}$ \\
\hline $\begin{array}{l}\text { PARTE } \\
\text { IV }\end{array}$ & $\begin{array}{l}\text { Alinhamento } \\
\text { Estratégico }\end{array}$ & $\begin{array}{l}\text { Barros (2007); Bruel, Santos e Moser (2003); } \\
\text { Pongatichat e Johnston (2008); Prieto (2006); } \\
\text { Vasconcelos (2001); } \\
\text { (em geral a seção 2.4) }\end{array}$ & $\begin{array}{l}\text { Explorar o alinhamento estratégico } \\
\text { de maneira geral dentro da empresa }\end{array}$ \\
\hline $\begin{array}{l}\text { PARTE } \\
\mathrm{V}\end{array}$ & Considerações Finais & $\begin{array}{l}\text { Barros Neto (1999); } \\
\quad \text { Silva (2003) }\end{array}$ & $\begin{array}{l}\text { Finalização da entrevista, esclarecer } \\
\text { dúvidas, ver possíveis contribuições do } \\
\text { entrevistado para a pesquisa }\end{array}$ \\
\hline
\end{tabular}

Fonte: Costa (2010). 
Figura 2 - Modelo conceitual de alinhamento estratégico



Fonte: Costa (2010).

Figura 3 - Exemplo de comparação das respostas em gráfico radar

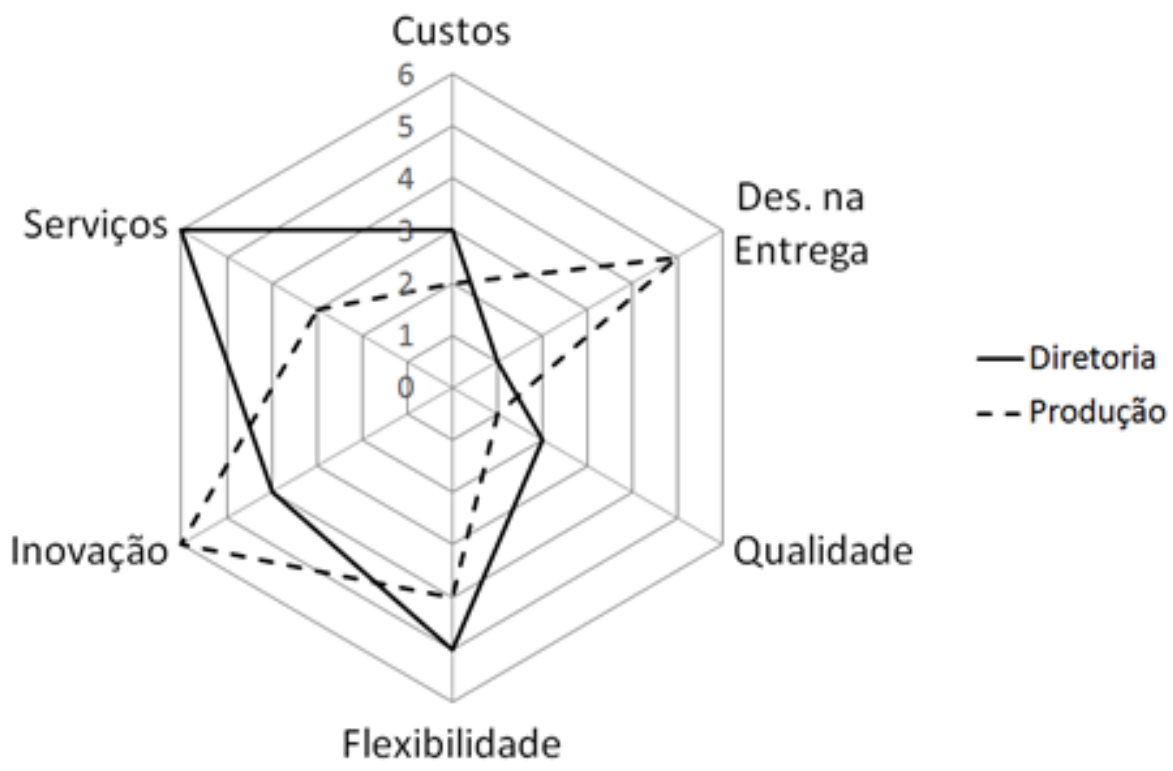

Fonte: Costa (2010).

Os questionários são comparados e, para isso, fazem-se o produto e a diferença de cada resposta da produção e da diretoria com seus itens correspondentes. Por exemplo, se a diretoria escalonou a redução de custos como sua terceira prioridade e a produção enxerga que para a empresa a redução de custos é a prioridade máxima, então se faz a diferença, que será 2 (3-1), e o produto, que será 3 (3x1). A diferença, porém, sofre uma ponderação de acordo com as respostas da diretoria, já que a direção da empresa é o foco do modelo.

A ponderação adotada por Costa (2010) foi inspirada na sequência de Fibonacci, como pode ser observado na Tabela 1.

O modelo de Costa (2010), portanto, avalia as seguintes variáveis referentes à análise das interações entre as respostas de ordenação da importância percebida dos critérios competitivos dos membros da diretoria e produção: (a) Soma das Diferenças Ponderadas (SDP): correspondente à soma das subtrações ponderadas pela sequência de Fibonacci das respostas dos dois membros; e

(b) Soma dos Produtos (SP): correspondente à soma das multiplicações diretas entre as respostas dos dois membros sem ponderação alguma.

Assumindo um gráfico com abscissa SP e ordenada SDP - coordenadas (SP;SDP), calculamse as duas situações teóricas que correspondem aos casos de maior alinhamento estratégico teórico (Ideal) e menor alinhamento estratégico teórico (Pior), resultando, respectivamente, em $(91 ; 0)$ e $(56 ; 108)$, que podem ser observadas na Tabela 2 .

A partir daí, é possível não somente uma mensuração do alinhamento estratégico como também sua expressão gráfica, conforme a Figura 4. 
Tabela 1 - Pesos atribuídos para as diferenças entre as respostas da diretoria e produção

\begin{tabular}{c|c|c|c|c|c|c}
\cline { 2 - 7 } & \multicolumn{3}{|c}{ MAIOR } & \multicolumn{3}{c}{ ESCALA DE PRIORIDADE } \\
\hline $\begin{array}{c}\text { ORDEM DE PRIORIDADE } \\
\text { DOS CRITÉRIOS DA DIRETORIA }\end{array}$ & $\mathbf{1}$ & $\mathbf{2}$ & $\mathbf{3}$ & $\mathbf{4}$ & $\mathbf{5}$ & $\mathbf{6}$ \\
\hline PESOS (PONDERAÇÃO) & $\mathbf{1 3}$ & $\mathbf{8}$ & $\mathbf{5}$ & $\mathbf{3}$ & $\mathbf{2}$ & $\mathbf{1}$ \\
\hline INSPIRADO NA SEQUÊNCIA DE FIBONACCI & $8+5$ & $5+3$ & $3+2$ & $2+1$ & $1+1$ & $1+0$ \\
\hline
\end{tabular}

Fonte: Costa (2010).

Tabela 2 - Simulação dos resultados para a pior e a melhor situações teóricas do modelo

\begin{tabular}{|c|c|c|c|c|c|c|}
\hline \multirow{2}{*}{$\begin{array}{l}\text { CRITÉRIOS } \\
\text { (C) }\end{array}$} & \multicolumn{6}{|c|}{ SITUAÇÃO IDEAL (EXEMPLO) } \\
\hline & DIRETORIA & PRODUÇÃO & $\begin{array}{c}\text { DIFERENÇA ABSOLUTA } \\
\text { (MÓDULO) }\end{array}$ & PRODUTO & PESOS & $\begin{array}{l}\text { DIFERENÇA } \\
\text { PONDERADA }\end{array}$ \\
\hline $\mathrm{C} 1$ & 14 & 14 & 0 & 1 & 13 & 0 \\
\hline $\mathrm{C} 2$ & 2 & 2 & 0 & 4 & 8 & 0 \\
\hline C3 & 3 & 3 & 0 & 9 & 5 & 0 \\
\hline $\mathrm{C} 4$ & 4 & 4 & 0 & 16 & 3 & 0 \\
\hline $\mathrm{C5}$ & 5 & 5 & 0 & 25 & 2 & 0 \\
\hline C6 & 6 & 6 & 0 & 36 & 1 & 0 \\
\hline \multicolumn{3}{|c|}{ SOMA } & 0 & 91 & - & 0 \\
\hline \multirow{2}{*}{$\begin{array}{l}\text { CRITÉRIOS } \\
\text { (C') }\end{array}$} & \multicolumn{6}{|c|}{ PIOR SITUAÇÃO (EXEMPLO) } \\
\hline & DIRETORIA & PRODUÇÃO & $\begin{array}{c}\text { DIFERENÇA ABSOLUTA } \\
\text { (MÓDULO) }\end{array}$ & PRODUTO & PESOS & $\begin{array}{r}\text { DIFERENÇA } \\
\text { PONDERADA }\end{array}$ \\
\hline $\mathrm{C1}^{\prime}$ & 1 & 6 & 5 & 6 & 13 & 65 \\
\hline $\mathrm{C} 2^{\prime}$ & 2 & 5 & 3 & 10 & 8 & 24 \\
\hline$C 3^{\prime}$ & 3 & 4 & 1 & 12 & 5 & 5 \\
\hline$C 4^{\prime}$ & 4 & 3 & 1 & 12 & 3 & 3 \\
\hline $\mathrm{C5}^{\prime}$ & 5 & 2 & 3 & 10 & 2 & 6 \\
\hline$C 6^{\prime}$ & 6 & 1 & 5 & 6 & 1 & 5 \\
\hline \multicolumn{3}{|c|}{ SOMA } & 18 & 56 & - & 108 \\
\hline
\end{tabular}

Fonte: Costa (2010).

Figura 4 - Visualização gráfica do alinhamento estratégico

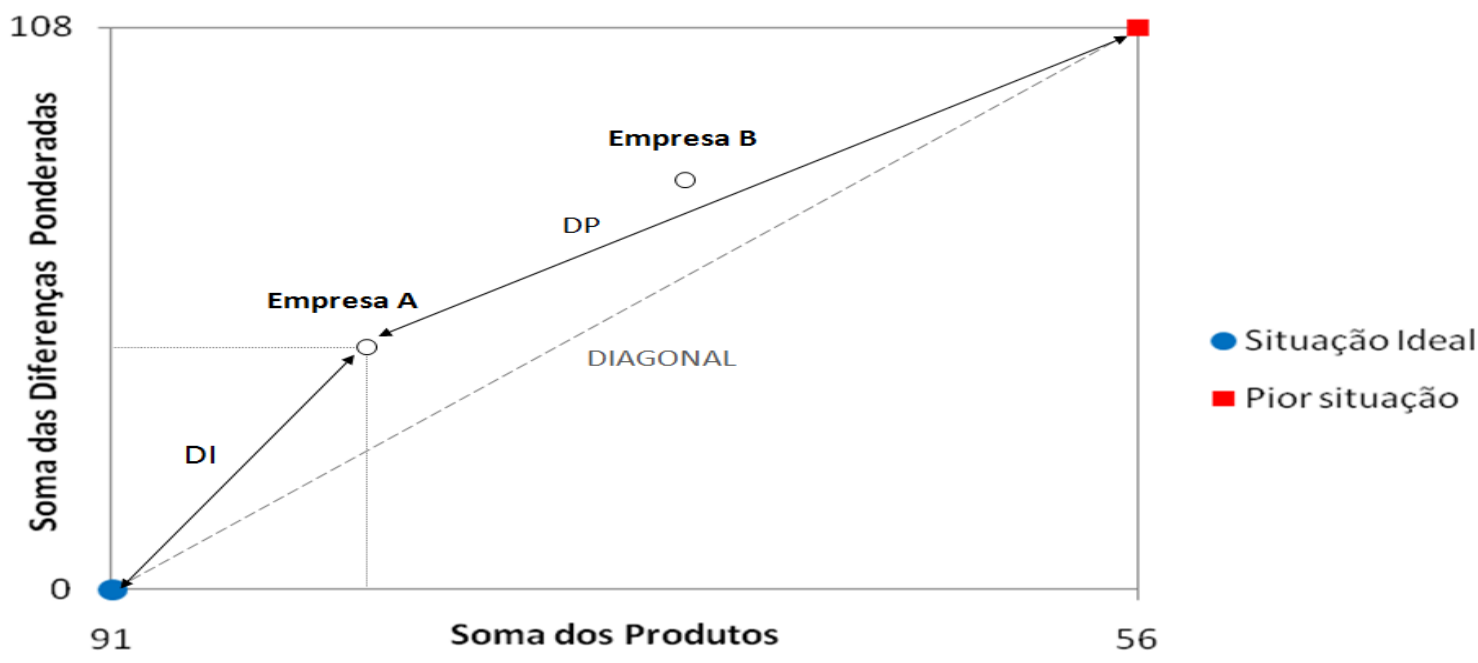

Fonte: Costa (2010). 
Nota-se que a situação ideal é representada pelo ponto azul, e a pior, pelo ponto vermelho. As empresas são dispostas no gráfico por meio das coordenadas SP e SDP. Por fim, o alinhamento estratégico é calculado pelas variáveis a seguir:

(a) distância do Ideal (DI): corresponde à distância do ponto em que se encontra a empresa até o ponto que marca a situação ideal (calculada por meio de trigonometria); e

(b) distância do Pior (DP): corresponde à distância do ponto em que se encontra a empresa até o ponto que marca a situação pior (calculada por meio de trigonometria).

Esse alinhamento é representado em porcentagem e obtido pela fórmula expressa na Tabela 3 , que ilustra, também, os valores de todas as variáveis tratadas nessa etapa do modelo para os casos da pior situação e situação ideal.

\section{Processo de análise crítica do modelo}

O desenvolvimento desse passo concentra-se principalmente no aprofundamento da etapa de análise de modelo ao qual uma modelagem matemática deve ser submetida, ou seja, foi realizada simulação, sistematização e interpretação dos resultados decorrentes do estudo para que fossem identificadas todas as características do comportamento do modelo, validando-o e encontrando suas vantagens e desvantagens. O fluxograma abaixo (Figura 5) representa exatamente a relação entre a modelagem e a análise do modelo de forma macro.

Caso validado, o modelo poderia ser livremente aplicado nas empresas. Caso contrário, o modelo passaria por um processo de otimização e revisão.

O modelo matemático analisado foi o adotado por Costa (2010) para a caracterização gráfica e matemática do alinhamento estratégico, que se trata da terceira etapa de aplicação e teste do modelo, conforme a Figura 1.

Tabela 3 - Variáveis do modelo de alinhamento estratégico

\begin{tabular}{|c|c|c|c|}
\hline \multirow{2}{*}{ DESCRIÇÃo } & \multirow{2}{*}{ SIGLA } & \multicolumn{2}{|c|}{ SITUAÇÃo } \\
\hline & & IDEAL & PIOR \\
\hline SOMA DAS DIFERENÇAS PONDERADAS & SDP & 0,0 & 108,0 \\
\hline SOMA DOS PRODUTOS & SP & 91,0 & 56,0 \\
\hline DISTÂNCIA DO IDEAL & DI & 0,0 & 113,5 \\
\hline DISTÂNCIA DO PIOR & DP & 113,5 & 0,0 \\
\hline SOMA DAS DISTÂNCIAS & $\mathrm{DI}+\mathrm{DP}$ & 113,5 & 113,5 \\
\hline $\begin{array}{l}\text { ALINHAMENTO DOS CRITÉRIOS COMPETITIVOS } \\
\qquad A C C=D P /(D I+D P)\end{array}$ & $\mathrm{ACC}$ & $100 \%$ & $0 \%$ \\
\hline
\end{tabular}

Fonte: Costa (2010).

Figura 5 - Fluxograma de análise metodológica utilizada

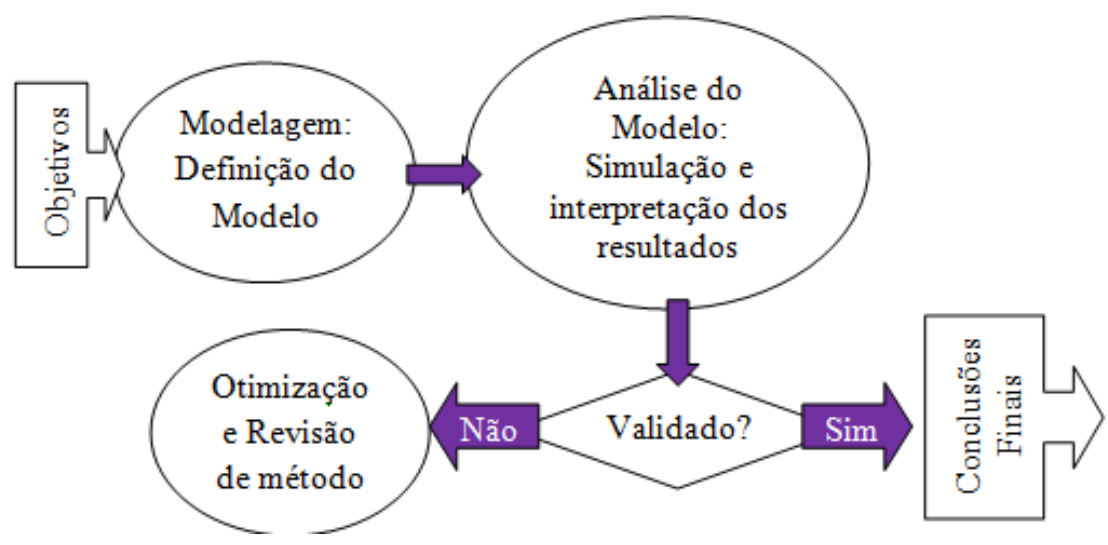

204 Costa, G. S.; Barros Neto, J. de P.; Vasconcelos, I. A. de; Soares, M. F. 
Sendo assim, o modelo foi submetido à situação ótima de possuir um banco de dados completo. Isso foi possível porque os valores que podem ser encontrados a partir da Soma dos Produtos e da Soma das Diferenças Ponderadas são variáveis discretas, gerando um número limitado de respostas.

Cada resposta da Diretoria deve interagir com as respostas da Produção, de forma a encontrar todos os arranjos possíveis. Para saber a quantidade final e organizar o algoritmo corretamente, utilizou-se a fórmula matemática dos Arranjos (Equação 1).

$A=\frac{n !}{(n-s) !}$

Eq. 1

A determinação do algoritmo baseou-se na impossibilidade de haver repetição dos seis algarismos de respostas de ordenamento dos critérios competitivos $(1,2,3,4,5,6)$ dentro de um mesmo caso. Então, foram estabelecidas, primeiro, todas as respostas em que a primeira questão do questionário foi colocada como a prioritária, a segunda como secundária e assim por diante, até que fossem esgotadas as possibilidades. Daí o processo era reiniciado com um novo elemento como prioritário.

Concluída essa etapa, iniciou-se o cálculo dos produtos e das diferenças, para que estas fossem ponderadas e os resultados gerassem a Soma dos Produtos e a Soma das Diferenças Ponderadas. Com esses dados, foi possível calcular o ACC, que representa percentualmente o alinhamento estratégico. Por tratar-se de um método visual e matemático, a geração de um gráfico que representasse todos os pontos é uma etapa fundamental deste estudo.

A simulação também permite uma análise do efeito da ponderação adotada por Costa (2010) para o cálculo das Somas das Diferenças
Ponderadas, além do comportamento dos pontos, possibilitando a verificação da forma da linha de tendência que permitiria uma classificação das empresas quanto a seu alinhamento estratégico.

Finalmente, de posse dos resultados oriundos da aplicação do modelo nas 14 empresas e da simulação gerada para o modelo, realizou-se uma análise crítica dos dados gerados conforme a seção de resultados a seguir.

\section{Resultados}

Nesta seção, apresentam-se os resultados obtidos da aplicação experimental do modelo em um conjunto de 14 empresas da indústria da construção civil, conforme detalhado no tópico 3.0.

\section{Aplicação inicial do modelo}

Para a identificação das três primeiras empresas, adotaram-se as siglas $\mathrm{JA}^{1}, \mathrm{PA}^{2}$ e $\mathrm{RQ}^{3}$. Os resultados apresentados a seguir baseiam-se no trabalho de Costa, Barros Neto e Vieira (2011).

Primeiramente, na Tabela 4, exibem-se os resultados da Parte III do questionário (questão 19), resumidamente, listando a empresa e as notas de seus representantes, e expondo as diferenças de visões entre eles sobre os critérios competitivos. Destaca-se a prioridade da Diretoria em cada um dos casos, o que é um indício para determinar a estratégia competitiva de cada construtora. A empresa menos alinhada é a PA. Pode-se ver que o que é mais prioritário para a Diretoria está em quinto lugar para a Produção.

$\mathrm{Na}$ Tabela 5, mostram-se os resultados dos cálculos do alinhamento dos critérios competitivos (ACC), conforme mostrado na metodologia

Tabela 4 - Resultados da Parte III (Critérios Competitivos) respondida pelos dois representantes de cada uma das empresas, o da Diretoria (DIR.) e o da Produção (PROD.)

\begin{tabular}{|c|c|c|c|c|c|c|c|c|c|c|c|c|c|c|c|}
\hline \multirow{2}{*}{ CRITÉRIOS } & \multicolumn{5}{|c|}{ EMPRESA JA } & \multicolumn{5}{|c|}{ EMPRESA PA } & \multicolumn{5}{|c|}{ EMPRESA RQ } \\
\hline & DIR. & . PROD. & D. A. & PROD. & D. P. & DIR. & PROI & D. A. & PROD. & D. P. & DIR. & \begin{tabular}{|l|} 
PROD. \\
\end{tabular} & D. A. & PROD. & D. P. \\
\hline CUSTOS & 2 & 5 & 3 & 10 & 8 & 3 & 2 & 1 & 6 & 5 & 3 & 4 & 1 & 12 & 5 \\
\hline $\begin{array}{l}\text { DESEMPENHO } \\
\text { NA ENTREGA }\end{array}$ & 3 & 4 & 1 & 12 & 5 & 1 & 5 & 4 & 5 & 13 & 4 & 2 & 2 & 8 & 3 \\
\hline QUALIDADE & 1 & 1 & 0 & 1 & 13 & 2 & 1 & 1 & 2 & 8 & 1 & 1 & 0 & 1 & 13 \\
\hline FLEXIBILIDADE & 4 & 3 & 1 & 12 & 3 & 5 & 4 & 1 & 20 & 2 & 6 & 3 & 3 & 18 & 1 \\
\hline INOVAÇÃO & 6 & 6 & 0 & 36 & 1 & 4 & 6 & 2 & 24 & 3 & 5 & 6 & 1 & 30 & 2 \\
\hline SERVIÇOS & 5 & 2 & 3 & 10 & 2 & 6 & 3 & 3 & 18 & 1 & 2 & 5 & 3 & 10 & 8 \\
\hline SOMATÓRIO & \multicolumn{2}{|c|}{ SOMA } & & 81,00 & 38,00 & \multicolumn{2}{|c|}{ SOMA } & & 75,00 & 76,00 & \multicolumn{2}{|c|}{ SOMA } & \multicolumn{3}{|c|}{$\begin{array}{ll}79,00 & 40,00\end{array}$} \\
\hline
\end{tabular}

\footnotetext{
${ }^{3}$ Em homenagem ao escritor cearense José de Alencar.

${ }^{4}$ Em homenagem ao escritor Patativa do Assaré.

${ }^{5}$ Em homenagem à escritora Raquel de Queiroz.
} 
Tabela 5 - Resultados do alinhamento dos critérios competitivos no estudo

\begin{tabular}{|c|c|c|c|c|c|c|c|}
\hline \multirow{2}{*}{ DESCRIÇÃO } & \multirow{2}{*}{ SIGLA } & \multicolumn{2}{|c|}{ SITUAÇÃO } & \multicolumn{3}{|c|}{ EMPRESAS } & \multirow{2}{*}{$\begin{array}{c}\text { MÉDIA } \\
\text { DAS } 3 \\
\text { EMPRESAS }\end{array}$} \\
\hline & & IDEAL & PIOR & $\mathbf{J A}$ & PA & $\mathbf{R Q}$ & \\
\hline SOMA DAS DIFERENÇAS PONDERADAS & S D P & 0,0 & 108,0 & 38,0 & 76,0 & 40,0 & 51,3 \\
\hline SOMA DOS PRODUTOS & S P & 91,0 & 56,0 & 81,0 & 75,0 & 79,0 & 78,3 \\
\hline DISTÂNCIA DO IDEAL & D I & 0,0 & 113,5 & 39,3 & 77,7 & 41,8 & 52,9 \\
\hline DISTÂNCIA DO PIOR & D P & 113,5 & 0,0 & 74,3 & 37,2 & 71,8 & 61,1 \\
\hline SOMA DAS DISTÂNCIAS & $\mathrm{D} I+\mathrm{D} P$ & 113,5 & 113,5 & 113,6 & 114,9 & 113,5 & 114,0 \\
\hline ALINHAMENTO DOS CRITÉRIOS COMPETITIVOS & A C C & $100 \%$ & $\mathbf{0 \%}$ & $65 \%$ & $32 \%$ & $63 \%$ & $54 \%$ \\
\hline DESALINHAMENTO DOS CRITÉRIOS COMPETITIVOS & $\mathrm{DCC}$ & $0 \%$ & $100 \%$ & $35 \%$ & $68 \%$ & $37 \%$ & $46 \%$ \\
\hline ALINHAMENTO + DESALINHAMENTO & $\mathrm{ACC}+\mathrm{DCC}$ & $100 \%$ & $100 \%$ & $100 \%$ & $100 \%$ & $100 \%$ & $100 \%$ \\
\hline
\end{tabular}

O quesito Custos também apresentou altos índices tanto para a Diretoria como para a Produção, tendo um dos melhores resultados em diferença absoluta. Isso se deve à grande importância do quesito no setor financeiro das empresas, sendo este, por sua vez, fundamental para as definições estratégicas de longo, médio e curto prazos.

Inversamente a ele estaria exatamente a flexibilidade, o que pode ser comprovado observando-se as três empresas. Ações de flexibilidade tornam os processos/serviços mais complexos e, muitas vezes, mais caros, afetando os custos e até mesmo necessitando de inovações, apesar de este quesito estar diretamente relacionado à satisfação do cliente e ser uma tendência do mercado nas mais diversas indústrias.

Já o quesito com piores respostas foi Inovação, o que não surpreende, tendo em vista que no Brasil em torno de $27 \%$ dos pesquisadores estão no setor privado, índice baixo em comparação com países desenvolvidos. Sendo assim, é esperado que não haja grandes investimentos em inovação.

Notou-se ainda que o quesito que apresentou as maiores diferenças absolutas foi o de Serviços, que pode estar relacionado diretamente ao sistema de comunicação da empresa ou com o entendimento do que seriam os serviços dentro da pesquisa. No primeiro caso, a disposição de recursos e as cobranças vindas do escritório podem gerar esse conflito de visão estratégica. O segundo caso enquadrar-se-ia em um dos pontos negativos do método, que é sua suscetibilidade às interações entre entrevistador e respondente.

Entre as três empresas, a mais alinhada em relação aos critérios competitivos é a JA (com 65\%), e a mais desalinhada é a PA (com 32\%), ficando a empresa RQ em posição intermediária, mas bem próxima da primeira colocada (com 63\%). A média das três empresas foi de 54\%. Nas Figuras 6 e 7, apresenta-se um comparativo entre as três empresas.
Enquanto a Empresa JA possui apenas uma obra em andamento, as Empresas PA e RQ possuem cinco e onze obras respectivamente. Nesse contexto, a Empresa JA aparece como a menos complexa do grupo, pois tem baixo volume de obras, atua somente na cidade de Fortaleza e somente para um público específico. Esse fator, apesar do empenho e capacitação dos envolvidos, favorece a Empresa JA a trabalhar com maior facilidade as questões de gestão empresarial, podendo ser um fator facilitador do alinhamento estratégico. Já as outras empresas têm um volume superior de obras, uma abrangência maior em sua atuação no mercado, tanto por tipo de cliente como geograficamente, fatores estes que podem desfavorecer o alinhamento estratégico interno nessas construtoras.

\section{Aplicação posterior do modelo}

Após a verificação inicial da aplicabilidade do modelo com as três empresas tratadas anteriormente, obteve-se o resultado do alinhamento estratégico com mais 14 empresas construtoras cearenses a partir do modelo proposto, culminando na ilustração do posicionamento das empresas na Figura 8, cujos resultados numéricos individuais encontram-se no Anexo. A empresa mais alinhada é a 11, e a menos alinhada é a 9, ambas com $91,6 \%$ e $8,7 \%$ respectivamente. A média de todas as construtoras analisadas foi de $57,3 \%$.

O critério competitivo mais citado, em média, como sendo o prioritário foi Qualidade, por ambos os representantes, Diretoria e Produção, sendo mais citada pelos representantes da Produção. Já os menos prioritários, em média, foram Serviços Associados, por parte da Diretoria, e Inovações, por parte da Produção (ver tabela no Anexo).

Os itens Custos e Desempenho na Entrega ficaram praticamente empatados, em média, para ambos os representantes, da Diretoria e da Produção. 
Figura 6 - Alinhamento dos critérios competitivos ALINHAMENTO DOS CRITÉRIOS COMPETITIVOS

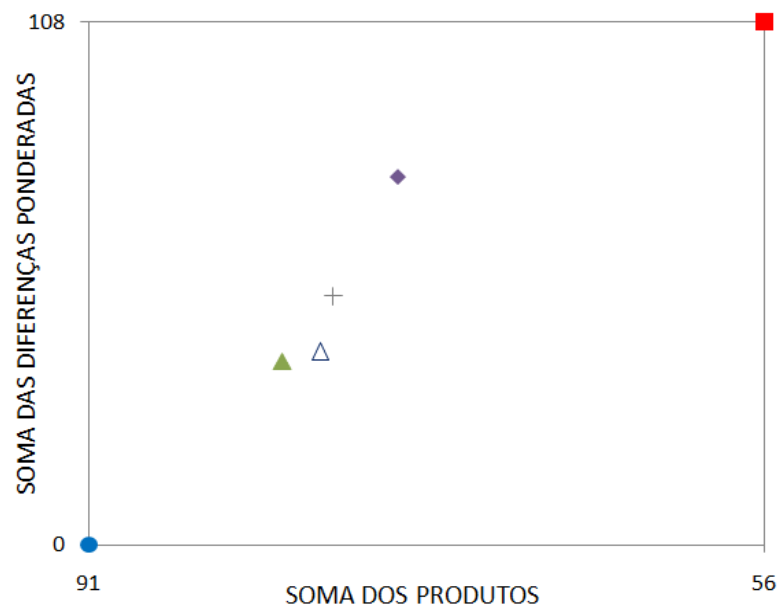

- Situação Ideal

n Pior situação

$\triangle$ Empresa JA

- Empresa PA

$\triangle$ Empresa RQ

+ Média das 3 Empresas

Figura 7 - Comparativo entre as três empresas participantes do estudo: JA, PA e RQ

\begin{tabular}{|c|c|c|}
\hline EMPRESA JA & EMPRESA PA & EMPRESA RQ \\
\hline \multicolumn{3}{|c|}{ SEDE DA EMPRESA (CIDADE) } \\
\hline Fortaleza-CE & Fortaleza-CE & Fortaleza-CE e Belém-PA \\
\hline \multicolumn{3}{|c|}{ ANO DE FUNDAÇÃO } \\
\hline Fundada em 1988 & Fundada em 1969 & Fundada em 1988 \\
\hline \multicolumn{3}{|c|}{ ÁREA DE ATUAÇÃO } \\
\hline $\begin{array}{l}\text { Sempre atuou somente com } \\
\text { incorporação e construção, foco } \\
\text { hoje em incorporação para } \\
\text { determinado público }\end{array}$ & $\begin{array}{c}\text { Começou como incorporadora, foca } \\
\text { hoje no mercado de obras } \\
\text { industriais, mas mantém a } \\
\text { versatilidade ainda atuando como } \\
\text { construtora e incorporadora }\end{array}$ & $\begin{array}{l}\text { Começou como incorporadora, } \\
\text { atualmente atua apenas como } \\
\text { construtora e faz uma experiência } \\
\text { com obras públicas }\end{array}$ \\
\hline \multicolumn{3}{|c|}{ ABRANGÊNCIA (ATUAÇÃO GEOGRÁFICA) } \\
\hline No estado do ceará (foco: fortaleza) & $\begin{array}{c}\text { Em todo o brasil (foco: norte e } \\
\text { nordeste) }\end{array}$ & Nas regiões norte e nordeste \\
\hline \multicolumn{3}{|c|}{ OBRAS EM ANDAMENTO } \\
\hline 1 obra em andamento & 5 obras em andamento & 11 obras em andamento \\
\hline \multicolumn{3}{|c|}{ PLANEJAMENTO ESTRATÉGICO } \\
\hline $\begin{array}{l}\text { Realiza formalmente, anualmente } \\
\text { com acompanhamento semestral }\end{array}$ & $\begin{array}{c}\text { Realiza informalmente, centrado na } \\
\text { visão dos diretores }\end{array}$ & $\begin{array}{l}\text { Realiza informalmente, com } \\
\text { decisões de natureza reativa }\end{array}$ \\
\hline \multicolumn{3}{|c|}{ PERFIL DO ALINHAMENTO DOS CRITÉRIOS COMPETITIVOS (ACC) } \\
\hline $\begin{array}{c}\text { Flexibilidade } \\
\mathrm{ACC}=65 \%\end{array}$ & $\begin{array}{c}\text { Flexibilidade } \\
\mathrm{ACC}=\mathbf{3 2 \%}\end{array}$ & $\mathrm{ACC}=63 \%$ \\
\hline
\end{tabular}


Figura 8 - Alinhamento dos critérios competitivos das 14 construtoras

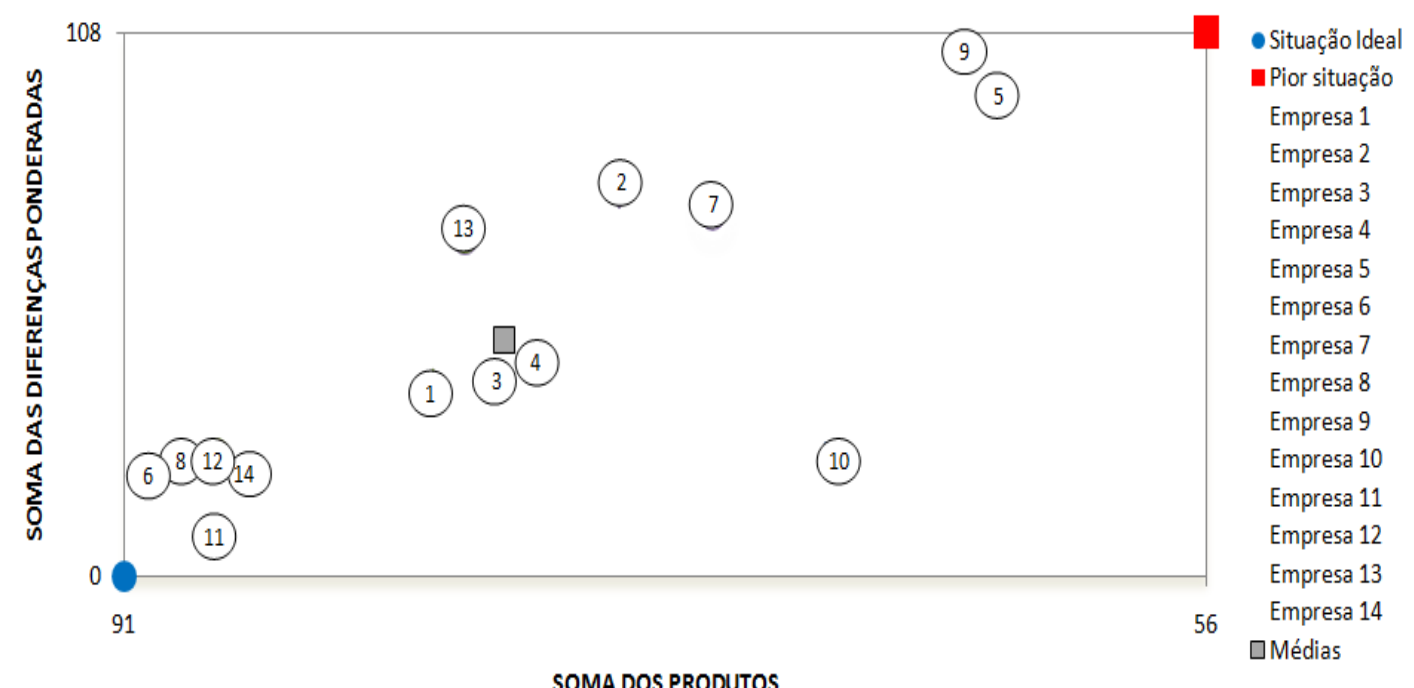

O item Flexibilidade não foi apontado como o mais prioritário em nenhuma situação, ou seja, nenhum dos entrevistados atribuiu nota " 1 " para este item, assim como nenhum representante da Produção apontou o item Inovações como sendo o mais prioritário.

Observa-se que o método pode ser utilizado como indicador para a melhoria contínua da organização, indicando pontos que necessitem de mais investimento, melhor distribuição de recursos ou de melhor abordagem na comunicação interna. Por exemplo, se frequentemente o item Flexibilidade apresenta baixa priorização tanto para a Produção quanto para a Diretoria, pode-se identificar que é uma oportunidade de melhoria a ser explorada pela organização.

Além disso, um desalinhamento estratégico muito acentuado indica também uma falha no sistema de gestão da empresa, pois um gerenciamento eficiente contribui para um alinhamento entre os diversos setores da organização.

\section{Análise crítica do modelo apresentado}

Para uma melhor exploração do modelo e da eficácia de sua representação, simularam-se todos os pontos diferentes que pudessem ser gerados por todas as respostas possíveis para os questionários, ou seja, 720 respostas para cada um deles, o que pode ser constatado pela fórmula do Arranjo, pois a ordem de disposição das respostas influencia no resultado. Observa-se que, sabendo que são seis elementos tomados seis a seis, substituindo na Equação 1, temos:
$A=\frac{n !}{(n-s) !}=\frac{6 !}{0 !}=720$

Eq. 2

Após o arranjo de todas as respostas possíveis para cada setor (Direção e Produção), calculou-se a Soma dos Produtos e a Soma das Diferenças Ponderadas, conforme a metodologia explicitada neste artigo. Isso foi feito com o auxílio do Excel e uma interação entre linhas e colunas, contendo cada uma das 720 respostas simuladas.

Para a simulação, cada uma das respostas da Diretoria tem de interagir com todas as respostas da Produção, resultando em 518.400 interações (720 x 720), porém se constatou que são gerados somente 556 pontos diferentes; os demais são repetições desses. Como a ponderação não está relacionada à pergunta do questionário, e sim à resposta da Diretoria, a diferença ponderada permanece a mesma, mudando somente sua posição conforme a resposta dada (vide exemplo na Tabela 6).

Observando o exemplo acima, percebe-se que é mais importante a combinação entre as respostas da Produção e da Diretoria do que a ordem das respostas em relação aos itens do questionário. Sendo assim, pode-se ter o mesmo ACC para mais de um grupo de respostas, como pode ser observado na Tabela 6 e na Tabela 7. Constatou-se que esse fato ocorre 164 vezes dentro das 720 respostas que deveria haver.

Como o parâmetro estabelecido foi exatamente o ACC, conclui-se, de fato, que estes dois casos exemplificados possuem o mesmo alinhamento estratégico, estando ambos à mesma distância do ideal. 
Tabela 6 - Casos A e B, ambos com o mesmo ACC

\begin{tabular}{c|c|c|c|c}
\hline \multicolumn{6}{c}{ CASO A = ACC = 92,13\% } \\
\hline & Diretoria & Produção & Produto & Diferença Ponderada \\
\hline Q1 & $\mathbf{1}$ & $\mathbf{1}$ & 1 & 0 \\
\hline Q2 & $\mathbf{2}$ & $\mathbf{2}$ & 4 & 0 \\
\hline Q3 & 3 & 3 & 9 & 0 \\
\hline Q4 & 6 & 4 & 24 & 2 \\
\hline Q5 & 5 & 5 & 25 & 0 \\
\hline Q6 & 4 & 6 & 24 & 6 \\
\hline \multicolumn{7}{c}{ Soma } \\
\hline \multicolumn{7}{|c|}{ CASO B = ACC = 92,13\% } \\
\hline Q1 & Diretoria & Produção & Produto & Diferença Ponderada \\
\hline Q2 & 5 & 6 & 24 & 6 \\
\hline Q3 & 1 & 5 & 25 & 0 \\
\hline Q4 & $\mathbf{2}$ & $\mathbf{2}$ & 1 & 0 \\
\hline Q5 & 6 & 4 & 24 & 0 \\
\hline Q6 & 3 & 3 & 9 & 2 \\
\hline \multicolumn{7}{|c|}{ Soma } & 87 & 8 \\
\hline
\end{tabular}

Tabela 7 - Casos C e D

\begin{tabular}{|c|c|c|c|c|}
\hline \multicolumn{5}{|c|}{ CASO C $=\mathbf{8 1 , 3 4 \%}$} \\
\hline & Diretoria & Produção & Produto & Diferença Ponderada \\
\hline Q1 & 1 & 1 & 1 & 0 \\
\hline Q2 & 2 & 2 & 4 & 0 \\
\hline Q3 & 4 & 3 & 12 & 3 \\
\hline Q4 & 6 & 4 & 24 & 2 \\
\hline Q5 & 5 & 5 & 25 & 0 \\
\hline Q6 & 3 & 6 & 18 & 15 \\
\hline \multicolumn{3}{|c|}{ Soma } & 84 & 20 \\
\hline \multicolumn{5}{|c|}{ CASO D $=\mathrm{ACC}=\mathbf{8 1 , 3 4 \%}$} \\
\hline & Diretoria & Produção & Produto & Diferença Ponderada \\
\hline Q1 & 1 & 1 & 1 & 0 \\
\hline Q2 & 2 & 2 & 4 & 0 \\
\hline Q3 & 5 & 3 & 15 & 4 \\
\hline Q4 & 4 & 4 & 16 & 0 \\
\hline Q5 & 6 & 5 & 30 & 1 \\
\hline Q6 & 3 & 6 & 18 & 15 \\
\hline \multicolumn{3}{|c|}{ Soma } & 84 & 20 \\
\hline
\end{tabular}

Pelo fato de os dois casos divergirem no terceiro ponto, poder-se-ia admitir que aquele que converge no quarto princípio é o mais alinhado, porém, se comparados somente os pontos de divergência, será possível analisar que o Caso D apresenta uma diferença ponderada superior na Q3, o que poderia indicar maior desalinhamento. Sendo muito sutis as distinções entre esses casos e levando-se em consideração a subjetividade da análise, admite-se que o método é eficaz em determinar que os dois casos representam empresas com o mesmo alinhamento estratégico.

Como esses exemplos não ocorrem em todas as situações, o valor não é reduzido à metade (360 pontos), mas 164 pontos são repetidos, resultando nos 556 pontos anteriormente citados. Subtraindose todos os pontos repetidos, seja pela primeira situação exposta ou pela segunda, obteve-se o gráfico da Figura 9.

A reta exposta no gráfico representa a tendência linear desses pontos, e sua equação é uma aproximação. $\mathrm{O}$ ponto verde representa as melhores situações teóricas, ou seja, quando as respostas da Diretoria e da Produção são 100\% convergentes, porque os dois setores deram as mesmas respostas. O ponto vermelho representa as piores situações teóricas, ou seja, quando as respostas são completamente divergentes. 
Figura 9 - Gráfico das possibilidades diferentes de resposta de alinhamento do modelo de Costa (2010)

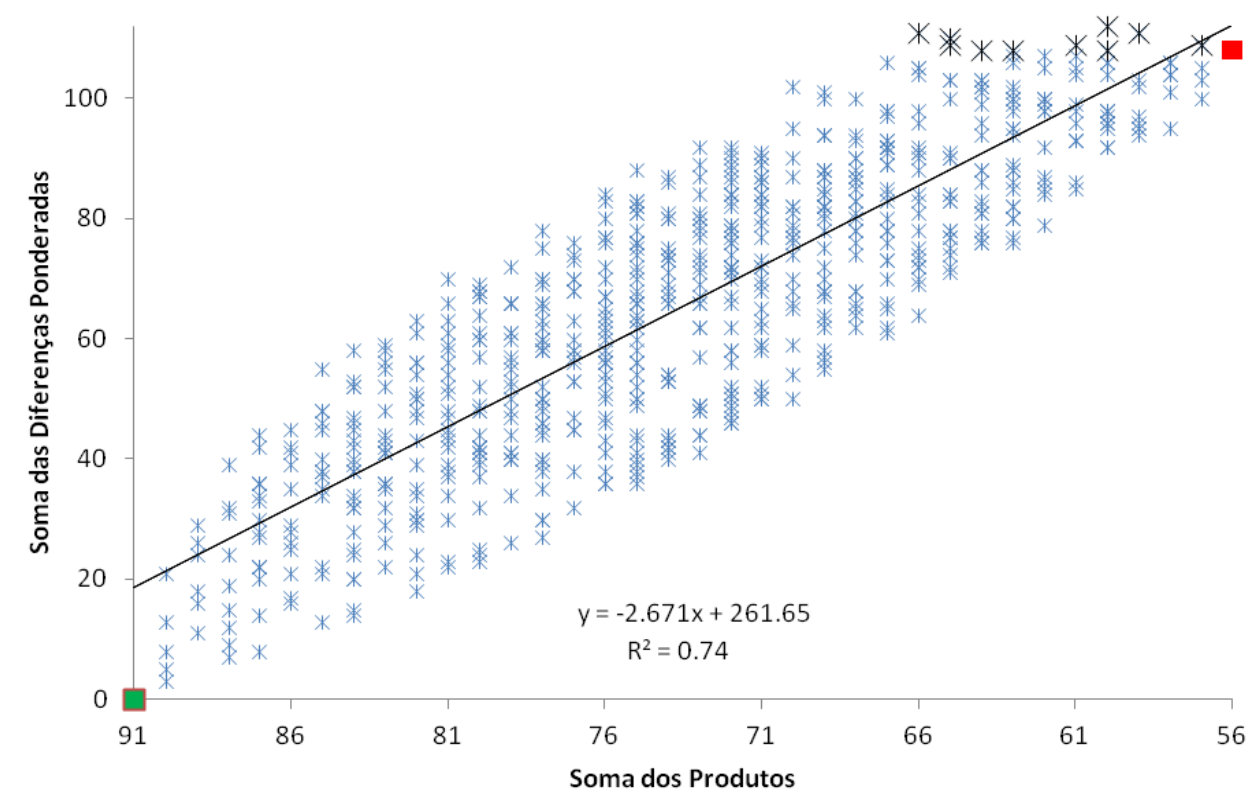

Os pontos pretos no gráfico são também interações de respostas possíveis, mas com uma peculiaridade: elas possuem uma Soma das Diferenças Ponderadas acima de 108. Isso ocorre devido à ponderação. Foram testadas outras ponderações que priorizassem a Diretoria, porém, em todas aquelas que foram testadas, ocorreram casos acima da Soma das Diferenças Ponderadas do pior caso teórico.

Não convém retirar a ponderação, primeiramente, porque, como é a Diretoria que define a estratégia (conforme pressuposto considerado no modelo), um desalinhamento em relação a ela é pior, como argumentado por Costa (2010).

As Somas das Diferenças para algumas situações poderiam ser iguais. Dessa forma, confirma-se que a Soma dos Produtos não pode ser usada de forma isolada.

Apesar de os pontos, cuja Soma das Diferenças Ponderadas está acima de 108, tornarem a explicação do método mais complexa, concluiu-se que não o invalida. É preciso ter em mente que a quantificação do Alinhamento Estratégico é feita pelo ACC, e não pelos valores individuais da Soma dos Produtos e da Soma das Diferenças Ponderadas.

Determinou-se, também, uma equação que permite o cálculo do ACC, sem que seja preciso calcular a distância para o pior ponto e a distância para o melhor ponto (Equação 3).

$A C C=\frac{\sqrt{(S P-56)^{2}+(108-S D P)^{2}}}{\sqrt{(S P-56)^{2}+(108-S D P)^{2}}+\sqrt{(91-S P)^{2}+(S D P)^{2}}}$

Eq. 3
Entre as limitações do método, destaca-se a sensibilidade dele às respostas dos entrevistados, que podem variar de acordo com o nível de compreensão das definições trabalhadas ou com sua disposição de representar fidedignamente a organização na pesquisa, ou seja, um membro da Produção, por exemplo, poderia responder buscando agradar seus superiores, e não a retratar de fato sua percepção da estratégia da empresa. Por isso, colaboradores mais antigos tendem a apresentar respostas mais alinhadas com as respostas da Diretoria. Para diminuir esse efeito, sugere-se que em uma mesma empresa seja entrevistado o maior número de colaboradores possível, tanto no âmbito de Diretoria quanto no de Produção.

\section{Conclusões e considerações finais}

Considera-se o objetivo principal deste trabalho alcançado, visto que se analisou o alinhamento entre as estratégias competitivas e as de produção em empresas de construção civil, com a proposição e aplicação de um método para medição e visualização/comparação do alinhamento. Focouse no aspecto qualitativo em desenvolver um modelo, e quantitativo ao aplicá-lo, incentivando o debate sobre ele e sugerindo-se, para futuras pesquisas, uma aplicação em maior número de construtoras, bem como em outras indústrias. Também se recomenda para trabalhos futuros analisar de forma mais aprofundada as lacunas entre as opiniões dos representantes de cada nível 
(gaps) e as consequências reais delas no desempenho da empresa.

Assim, entre as 14 empresas analisadas, conclui-se que a empresa mais alinhada é a 11, e que a menos alinhada é a 9. O item Qualidade foi apontado como o mais prioritário por ambos os representantes, da Diretoria e da Produção, enquanto o item Flexibilidade não foi apontado por nenhum dos entrevistados como o principal na ordem de prioridade.

As estratégias competitivas das empresas foram analisadas, e abordou-se a estratégia de produção através da identificação dos critérios competitivos priorizados pelas empresas de acordo com seu mercado de atuação e a percepção de seus representantes.

A partir do modelo aplicado e do perfil das empresas estudadas e de seus representantes, verificou-se a existência de algumas hipóteses, que poderão ser aprofundadas em estudos futuros:

(a) quanto maior a empresa, menor o alinhamento estratégico - quanto maior for o porte da construtora, maior o número de obras em andamento e/ou maior o número de colaboradores, menor tenderá a ser o alinhamento estratégico, pois mais difícil será a comunicação interna, a difusão e a compreensão da estratégia da empresa;

(b) quanto mais tempo de empresa tiverem os respondentes da pesquisa, maior tenderá a ser o alinhamento estratégico - quanto mais tempo de convivência com a equipe da empresa e com a realidade dela, mais os representantes se conhecerão e entenderão o cotidiano da empresa, facilitando o alinhamento; e

(c) quanto mais organizada a empresa em termos de gestão, mais favorecido será o alinhamento, pois, independentemente da estrutura e porte da organização, se bem administrada, ela poderá repassar, desdobrar, sua estratégia a partir de uma boa comunicação entre os representantes.

Pode-se verificar certa coerência entre os resultados de alinhamento obtidos individualmente por cada empresa e seu respectivo perfil, o que ajuda a endossar a lógica sugerida nas hipóteses descritas acima.

Vale ressaltar que houve tentativa de maior contato com os representantes após as entrevistas. Tentouse obter dados referentes ao desempenho das empresas, visando relacionar o grau de alinhamento e seu desempenho, conforme sugere a literatura (e.g. POWELL, 1992), porém existiram dificuldades de as empresas fornecerem algumas informações, por vezes sigilosas. Encontrou-se dificuldade em mostrar os resultados obtidos com o modelo para os representantes das empresas, visando a uma maior exposição dele, o que se deixa como sugestão para outras etapas da pesquisa.

A principal contribuição desta pesquisa para a literatura pertinente ao tema está no diagnóstico da percepção dos representantes das empresas (em diferentes níveis da hierarquia), a partir da avaliação da empresa através de método objetivo que fornece um valor final para o alinhamento estratégico dela (ACC), permitindo a representação desse nível em formato gráfico (Figura 17 e Tabela 7), o que facilita a realização de comparação entre empresas, além de preencher essa lacuna do conhecimento, pois, conforme a literatura, a mensuração do nível de alinhamento estratégico de empresas ainda não havia sido estudado de forma visual/gráfica (PRIETO, 2006).

Entendem-se como limitações do trabalho:

(a) apenas dois respondentes em cada construtora, porém o foco é confrontar opiniões e propor um modelo de medição, dependendo do porte da empresa - recomenda-se uma amostra maior de participantes e um cuidado maior na análise dos resultados e comparações;

(b) a revisão de estratégia competitiva fortemente focada em Porter $(1991,1992)$ - para o intuito deste trabalho admitiu-se como sendo a apropriada; e

(c) não se realizou nenhuma avaliação formal dos participantes quanto ao questionário utilizado porém, informalmente, se verificou que alguns representantes do setor de produção não conseguiram responder a todas as perguntas do questionário, mas essa ausência de respostas foi um resultado importante neste contexto, pois se tratava em geral de perguntas sobre estratégia, e os respondentes não tinham acesso às informações, portanto, dificultando a coerência entre os entrevistados.

Isso aconteceu fortemente na empresa PA, a mais desalinhada, e na RQ. Já não se evidenciou isso na empresa JA. Com relação a membros da Diretoria, somente um representante da empresa RQ encontrou dificuldades em responder às questões da entrevista quanto às indagações sobre alinhamento.

Realizou-se com sucesso a simulação de todas as possibilidades de resultado do modelo proposto por Costa (2010), sendo este de mensuração e expressão gráfica do alinhamento estratégico entre as visões da Direção e da Produção em empresas de construção civil, mas com potencial para ser aplicado em outras indústrias e/ou empresas, o que 
possibilitou maior aprofundamento e compreensão do modelo.

A partir dos dados colhidos, foi possível constatar que os pontos tendem a uma linearidade e que há uma limitação de 556 valores possíveis para os resultados do alinhamento. Concluiu-se que, para aplicação das diferenças, é preciso que estas recebam uma ponderação, ou não serão representativas, assim como a Soma dos Produtos sem a Soma das Diferenças Ponderadas. De fato, é necessário que os dois sejam analisados conjuntamente, o que ratificou a eficiência de medição do alinhamento proposto, que devolve um resultado percentual de alinhamento estratégico.

Como trabalhos futuros, no que concerne ao método em si, pretende-se determinar a linha fronteiriça proposta por Costa (2010) que caracterizaria as empresas mais alinhadas ou menos alinhadas, criar os níveis de fronteira a partir do gráfico da simulação, criar um gráfico em 3D (SP, SDP, ACC) e discutir a Curva de Tendência (Equação de ACC em função somente de SP e SDP), além de inserir explicações sobre os pontos equidistantes na metodologia e nos resultados do modelo proposto.

\section{Referências}

ALVES, T. C. L.; COSTA, G. S.; BARROS NETO, J. de P. Creating Value in Housing Projects: the use of post-occupancy analysis to develop new projects. In: CONSTRUCTION RESEARCH CONGRESS, Seatle, 2009.

Proceedings... Reston, Virginia: ASCE, 2009. v. 2. p. 1105-1114.

BARROS, L. A. M. de. Alinhamento Estratégico.São Paulo, 2007. Tese (Doutorado em Engenharia Civil) - Escola de Engenharia, Universidade de São Paulo, São Paulo, 2007.

BARROS NETO, J. de P. Proposta de Modelo de Formulação de Estratégia de Produção Para Pequenas Empresas de Construção Habitacional. Porto Alegre, 1999. Tese (Doutorado em Engenharia Civil) - Escola de Engenharia, Universidade Federal do Rio Grande do Sul, Porto Alegre, 1999.

BARROS NETO, J. P.; ALVES, T. C. L. Análise Estratégica da Implementação da Filosofia Lean em Empresas Construtoras. In: SIMPÓSIO DE ADMINISTRAÇÃO DA PRODUÇÃO, LOGÍSTICA E OPERAÇÕES

INTERNACIONAIS, 11., São Paulo, SP, 2008. Anais... São Paulo, 2008.
BORELLA, M. R. de C.; PADULA, A. D. Alignment Between the Supply, Manufacturing and Distribution Strategies and the Business Strategy. Journal of Operations and Supply Chain Management, v. 3, n. 2, jul./dec. 2010.

BRUEL, A.; SANTOS, A.; MOSER, L. Análise do Foco e Coerência da Estratégia de Uma Empresa de Construção Civil. In: SIMPÓSIO BRASILEIRO DE GESTÃO E ECONOMIA DA CONSTRUÇÃO, São Carlos, 2003. Anais... São Carlos: UFSCAR, 2003.

CARVALHO, M. M. de; LAURINDO, F. J. B. Estratégia Competitiva: dos conceitos à implementação. 2. ed. São Paulo: Atlas, 2007.

COSTA, D. B. Diretrizes Para Concepção, Implementação, e Uso de Sistemas de Indicadores de Desempenho Para Empresas de Construção Civil. 174 f. Porto Alegre, 2003. Dissertação (Mestrado em Engenharia Civil) Programa de Pós-Graduação em Engenharia Civil, Univesidade Federal do Rio Grande do Sul, Porto Alegre, 2003.

COSTA, G. S. Alinhamento Estratégico em Construtoras Cearenses. 188 p. Fortaleza, 2010. Dissertação (Mestrado em Engenharia Civil) Programa de Pós-Graduação em Engenharia Civil, Universidade Federal do Ceará, 2010.

COSTA, G. S.; BARROS NETO, J. P. Estudo de Caso Sobre o Alinhamento Estratégico em Uma Construtora na Capital Cearense. In: CONGRESSO NACIONAL DE EXCELÊNCIA EM GESTÃO, 6., Niterói, RJ. Anais... Niterói, 2010.

COSTA, G. S.; ROLA, E. S.; AZEVEDO, M. J. Uma Discussão Sobre Critérios Competitivos da Produção em Empresas que Implantaram a Construção Enxuta. In: ENCONTRO DE ENSINO E PESQUISA EM ADMINISTRAÇÃO E CONTABILIDADE, 32., São Paulo, 2009. Anais... São Paulo: EnANPAD, 2009.

COSTA, G. S.; BARROS NETO, J. P.; VIEIRA, J. P. P. Desenvolvendo Um Modelo de Alinhamento Estratégico e Aplicando em Empresas Construtoras Cearenses. In: SIMPÓSIO DE ADMINISTRAÇÃO DA PRODUÇÃO, LOGÍSTICA E OPERAÇÕES INTERNACIONAIS, 14., São Paulo, MG, 2011. Anais... São Paulo, 2011.

COSTA, G. S. et al. Alinhamento Estratégico em Empresas que Implantaram a Construção Enxuta em Fortaleza/CE. In: SIMPÓSIO BRASILEIRO DE GESTÃO E ECONOMIA DA CONSTRUÇÃO, 6., João Pessoa, 2009. Anais... João Pessoa, 2009. 
COSTA, G. S.; VIEIRA, J. P. P.; BARROS

NETO, J. de P. Análise da Produção Científica em Estratégia Com Foco na Construção Civil: ENTAC e SIBRAGEC de 2000 a 2009. In: ENCONTRO NACIONAL DE TECNOLOGIA DO AMBIENTE CONSTRUÍDO, 13., Canela, 2010. Anais... Canela, RS: ENTAC, 2010.

CRAGG, P.; KING. M.; HUSSIN, H. IT Aligment and Firm Performance in Small Manufacturing Firms. Journal of Strategic Information Systems, v. 11, p. 109-132, 2002.

GIL, A. C. Como Elaborar Projetos de Pesquisa. 5. ed. São Paulo: Atlas, 2008.

GHOBRIL, A. N.; MOORI, R. G. Alinhamento Estratégico Entre Indústrias de Bens de Capital e e Alimentos: uma análise com base em Miles e Snow. In: ENCONTRO DE ENSINO E PESQUISA EM ADMINISTRAÇÃO E CONTABILIDADE, Rio de Janeiro, 2007. Anais... Rio de Janeiro, 2007.

HENDERSON, J. C.; VENKATRAMAN, N. Stategic Alignment: leveraging information technology for transforming organizations. In: IBM Systems Journal, Armonk, v. 32, n. 1, p. 472-484, 1993.

JOSHI, M. P.; KATHURIA, R.; PORTH, S. J. Aligment of Strategic Priorities and Performance: an integration of operations and strategic management perspectives. Journal of Operations Management, v. 21, p. 353-369, 2003.

KAPLAN, R. S.; NORTON, D. P. Alinhamento: usando o balanced scorecard para criar sinergias corporativas. Rio de Janeiro: Elsevier, 2006.

KATHURIA, R.; JOSHI, M. P.; PORTH, S. J. Organizational Alignment and Performance: past, present and future. Management Decision, v. 45, n. 3, p. 503-517, 2007.

PAIVA, E. L.; CARVALHO JUNIOR, J. M.; FENSTERSEIFER, J. E. Estratégia de Produção e de Operações: conceitos, melhores práticas, visão de futuro. 2. ed. Porto Alegre: Bookman, 2009.

PIRES, S. Gestão Estratégica da Produção. Piracicaba: Ed. Unimep, 1995.

PONGATICHAT, P.; JOHNSTON, R. Exploring Strategy-Misaligned Performance Measurement. International Journal of Productivity and Performance Management, v. 57, n. 3, p. 207-22, 2008.
PORTER, M. E. Estratégia Competitiva: técnicas para análise de indústrias e da concorrência. 9. ed. Rio de Janeiro: Campus, 1991.

PORTER, M. E. Vantagem Competitiva: criando e sustentando um desempenho superior. 7. ed. Rio de Janeiro: Campus, 1992.

POWELL, T. C. Organizational Alignment as Competitive Advantage. Strategic Management Journal, v. 13, n. 2, p. 119-134, 1992.

PRIETO, V. C. Análise de Modelos de Alinhamento Estratégico Interno. São Paulo, 2006. Dissertação (Mestrado em Engenharia Civil) - Escola Politécnica da Universidade de São Paulo, São Paulo, 2006.

SILVA, E. M. Alinhamento das Estratégias Competitivas Com as Estratégias de Produção: estudo de caso no pólo moveleiro de VotuporangaSP. São Carlos, 2003. Dissertação (Mestrado em Engenharia Civil) - Escola de Engenharia de São Carlos, Universidade de São Paulo, São Carlos, 2003.

SILVA, M. A. C. Estratégias Competitivas na Indústria da Construção Civil. Rio de Janeiro, 1995. In: ENCONTRO NACIONAL DE TECNOLOGIA DO AMBIENTE CONSTRUÍDO, 1995. Anais... Rio de Janeiro, 1995.

SKINNER, W. Manufacturing: missing link in corporate strategy. Havard Business Review, may/june 1969.

SLACK, N. et al. Administração da Produção. São Paulo: Atlas, 1997.

SUN, H.; HONG, C. The Alignment Between Manufacturing and Business Strategies: its influence on business performance. Technovation, v. 22, p. 699-705, 2002.

VASCONCELOS, F. Safári de Estratégia, Questões Bizantinas e a Síndrome do Ornitorrinco: Uma análise empírica dos impactos da diversidade teórica em estratégia empresarial sobre a prática dos processos de tomada de decisão estratégica. In: ENCONTRO DE ENSINO E PESQUISA EM ADMINISTRAÇÃO E CONTABILIDADE, 31., Campinas, SP, 2001. Anais... Campinas, 2001.

VENKATRAMAN, N.; CAMILLUS, J. C. Exploring the Concept of 'Fit' in Strategic Management. Academy of Management Review, v. 9, n. 3, p. 513-525, 1984.

WHEELWRIGHT, S. C.; HAYES, R. H. Competing Through Manufactuting. Havard Business Review, Boston, v. 63, n. 1, p. 99-109, jan./feb. 1985. 
ANEXO - Resultados

Tabela (notas e cálculos para as 14 construtoras)

\begin{tabular}{|c|c|c|c|c|c|c|c|c|c|c|c|c|c|c|c|c|c|c|c|c|c|c|c|c|c|c|c|c|c|c|c|}
\hline \multirow{2}{*}{\multicolumn{3}{|c|}{ DESCRIÇÃO }} & \multicolumn{27}{|c|}{ EMPRESAS } & \multirow{2}{*}{\multicolumn{2}{|c|}{ MÉDIAS }} \\
\hline & & & \multicolumn{2}{|c|}{$1(J A)$} & \multicolumn{2}{|c|}{$2(\mathrm{PA})$} & $3(\mathrm{RQ})$ & \multicolumn{2}{|c|}{4} & \multicolumn{2}{|l|}{5} & \multicolumn{2}{|l|}{6} & \multicolumn{2}{|l|}{7} & \multicolumn{2}{|l|}{8} & \multicolumn{2}{|c|}{9} & \multicolumn{2}{|c|}{10} & \multicolumn{2}{|c|}{11} & \multicolumn{2}{|c|}{12} & \multicolumn{2}{|c|}{13} & \multicolumn{2}{|c|}{14} & & \\
\hline \multicolumn{3}{|c|}{ CRITÉRIOS COMPETITIVOS } & D & $\mathbf{P}$ & D & $\mathbf{P}$ & D $P$ & D & $\mathbf{P}$ & D & $\mathbf{P}$ & D & $\mathbf{P}$ & D & $\mathbf{P}$ & D & $\mathbf{P}$ & D & $\mathbf{P}$ & D & $\mathbf{P}$ & D & $\mathbf{P}$ & D & $\mathbf{P}$ & D & $\mathbf{P}$ & D & $\mathbf{P}$ & $D$ & $P$ \\
\hline \multirow{6}{*}{ 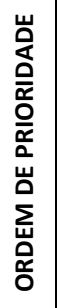 } & \multicolumn{2}{|l|}{ CUSTOS } & 2 & 5 & 3 & 2 & \begin{tabular}{|l|l}
3 & 4 \\
\end{tabular} & 3 & 3 & 6 & 1 & 3 & 3 & 3 & 1 & 1 & 2 & 5 & 3 & 3 & 6 & 3 & 3 & 1 & 1 & 5 & 3 & 1 & 1 & 3,0 & 2,7 \\
\hline & \multicolumn{2}{|l|}{ DESEMPENHO NA ENTREGA } & 3 & 4 & 1 & 5 & 4 & 5 & 1 & 4 & 3 & 2 & 1 & 2 & 5 & 3 & 3 & 3 & 1 & 1 & 5 & 1 & 1 & 4 & 3 & 4 & 2 & 2 & 3 & 2,8 & 2,8 \\
\hline & \multicolumn{2}{|l|}{ QUALIDADE } & 1 & 1 & 2 & 1 & \begin{tabular}{l|l}
1 & 1 \\
\end{tabular} & 1 & 2 & 3 & 2 & 1 & 2 & 1 & 3 & 2 & 1 & 6 & 2 & 2 & 1 & 2 & 2 & 3 & 2 & 2 & 1 & 3 & 2 & 2,1 & 1,6 \\
\hline & \multicolumn{2}{|l|}{ FLEXIBILIDADE } & 4 & 3 & 5 & 4 & \begin{tabular}{l|l}
6 & 3
\end{tabular} & 6 & 5 & 2 & 4 & \begin{tabular}{l|l}
4 & 2
\end{tabular} & 4 & 6 & 2 & 4 & 4 & 2 & 4 & 5 & 3 & 5 & 4 & 5 & 5 & 3 & 5 & 4 & 6 & 4,4 & 4,0 \\
\hline & \multicolumn{2}{|l|}{ INOVAÇÕES } & 6 & 6 & 4 & 6 & \begin{tabular}{l|l}
5 & 6 \\
\end{tabular} & 4 & 6 & 5 & 5 & 5 & 5 & 4 & 6 & 5 & 6 & 1 & 6 & 4 & 4 & 4 & 6 & 2 & 4 & 1 & 4 & 5 & 4 & 3,9 & 5,3 \\
\hline & \multicolumn{2}{|l|}{ SERVIÇOS ASSOCIADOS } & 5 & 2 & 6 & 3 & \begin{tabular}{l|l}
2 & 5
\end{tabular} & 2 & 4 & 1 & 6 & 6 & 6 & 5 & 4 & 6 & 5 & 4 & 5 & 6 & 2 & 6 & 5 & 6 & 6 & 6 & 6 & 6 & 5 & 4,8 & 4,6 \\
\hline & SOMA DAS DIFERENÇAS & $P$ & 38,0 & , 00 & 76,0 & & 40,00 & 44 & 1,00 & 94,0 & & $21,0 c$ & & 72,0 & & 24,0 & & 102, & 00 & 24,0 & & 9,00 & 00 & 24, & 1,00 & $67, \mathrm{C}$ &, 00 & 22 , & & & 5,93 \\
\hline & SOMA DOS PRODUTOS & SP & 81,0 & 00 & 75,0 & & 79,00 & 78 & 3,00 & 63,0 & & 90,00 & & 72,0 & & 89,0 & & 64,0 & & $68, C$ & & 88,0 & 00 & 88, &, 00 & 80, &, 00 & 87, & & & 3,71 \\
\hline & DISTÂNCIA DO IDEAL & וم & 39,2 & 29 & 77,6 & & 41,76 & 45 & 88 & 98,0 & & 21,02 & & 74,4 & & 24,0 & & 105 , & 51 & 33,2 & & 9,45 & & 24, & 19 & 67, & ,90 & 22 , & & 48, & 3,92 \\
\hline 芑 & DISTÂNCIA DO PIOR & U & 74,3 & 33 & 37,2 & & 71,78 & 67 &, 68 & 15,6 & & 93,41 & & 39,4 & & 90,2 & & 10,0 & 00 & $84, \varepsilon$ & & 104, & 1,04 & 89,8 & 89 & 47, &, 51 & 91, & & & 5,53 \\
\hline 它 & SOMA DAS DISTÂNCIAS & $D I+D P$ & 113, & 3,62 & 114 & & 113,55 & 113 & 3,56 & 113,7 & & 114,4 & & 113,8 & & 114,3 & & 115 , & 51 & 118 & & 113 & 3,53 & 114 & 4,08 & 115 , & 5,40 & 113 & & 114 & 4,45 \\
\hline & ALINHAMENTO DOS CRITÉRIOS COMPETITIVOS & ACC & 65,4 & $4 \%$ & 32,4 & & $63,2 \%$ & 59 , & $6 \%$ & 13,8 & & $81,6 \%$ & & 34,6 & & 78,9 & & 8,7 & $7 \%$ & 71,9 & & 91,6 & $6 \%$ & 78,8 & $8 \%$ & 41,2 & $2 \%$ & 80, & & &, $3 \%$ \\
\hline & $\begin{array}{l}\text { DESALINHAMENTO DOS CRITÉRIOS } \\
\text { COMPETITIVOS }\end{array}$ & DCC & 34,6 & $6 \%$ & 67,6 & & $36,8 \%$ & 40 , & ,4\% & 86,2 & & $18,4 \%$ & & 65,4 & & 21,1 & & 91,3 & & 28,1 & & 8,49 & $4 \%$ & 21,2 & , $\%$ & 58,8 & $8 \%$ & 19, & & &, $7 \%$ \\
\hline
\end{tabular}

Nota: Legenda:

$\mathrm{D}=$ representante da diretoria;

$\mathrm{P}=$ representante da produção;

$\mathrm{JA}=$ josé de alencar;

$P A=$ patativa do assaré; e $R Q=$ raquel de queiroz.

214 Costa, G. S.; Barros Neto, J. de P.; Vasconcelos, I. A. de; Soares, M. F. 


\section{George Silva Costa}

Departamento de Engenharia Estrutural e Construcão Civil, Centro de Tecnologia | Universidade Federal do Ceará | Campus do Pici, s/n, Bloco 710, Pici | Fortaleza - CE - Brasil | CEP 60455-760 | Tel.: (85) 3366-9600 | E-mail: georgesilvacosta@yahoo.com.br

\section{José de Paula Barros Neto}

Departamento de Engenharia Estrutural e Construção Civil, Centro de Tecnologia | Universidade Federal do Ceará |

E-mail: jpbarros@ufc.br

\section{luri Aragão de Vasconcelos}

Departamento de Engenharia Estrutural e Construção Civil, Centro de Tecnologia | Universidade Federal do Ceará |

E-mail: iuriav.ufc@gmail.com

\section{Marcella Facó Soares}

Departamento de Engenharia Estrutural e Construção Civil, Centro de Tecnologia | Universidade Federal do Ceará | E-mail: marcellafs@gmail.com

\section{Revista Ambiente Construído}

Associação Nacional de Tecnologia do Ambiente Construído

Av. Osvaldo Aranha, $99-3^{\circ}$ andar, Centro

Porto Alegre - RS - Brasil

CEP $90035-190$

Telefone: +55 (51) 3308-4084

Fax: +55 (51) 3308-4054

www.seer.ufrgs.br/ambienteconstruido

E-mail: ambienteconstruido@ufrgs.br 